\title{
Overexpression of Wnt-1 in thyrocytes enhances cellular growth but suppresses transcription of the thyroperoxidase gene via different signaling mechanisms
}

\author{
Won Bae Kim ${ }^{1,2}$, Christopher J Lewis ${ }^{1}$, Kelly D McCall ${ }^{1}$, Ramiro Malgor ${ }^{1}$, Aimee D Kohn ${ }^{3,4}$, Randall \\ T Moon ${ }^{3}$ and Leonard D Kohn ${ }^{1}$ \\ ${ }^{1}$ Edison Biotechnology Institute and College of Osteopathic Medicine, Ohio University, The Ridges, Athens, Ohio 45701, USA \\ ${ }^{2}$ Department of Internal Medicine, Asan Medical Center, University of Ulsan College of Medicine, 388-1 Pungnap-dong, Songpa-gu, Seoul 138-736, South \\ Korea \\ ${ }^{3}$ The Howard Hughes Medical Institute and ${ }^{4}$ The Department of Hematology, University of Washington, Seattle, Washington 98195 , USA \\ (Requests for offprints should be addressed to L D Kohn; Email: Ikohn1@rrohio.com, kohnl@ohio.edu)
}

\begin{abstract}
Wnt binding to cell surface receptors can activate a 'canonical' pathway that increases cellular $\beta$-catenin or a 'noncanonical' $\mathrm{Ca}^{++}$pathway which can increase protein kinase C (PKC) activity. Although components of both Wnt/ $\beta$-cateninsignaling pathways exist in thyrocytes, their biological role is largely unknown. In evaluating the biological role of Wnt signaling in differentiated FRTL-5 thyroid cells, we showed that TSH increased canonical Wnt-1 but, surprisingly, decreased the active form of $\beta$-catenin. Transient overexpression of Wnt-1 or $\beta$-catenin in FRTL-5 cells increased active $\beta$-catenin (ABC), decreased thyroperoxidase (TPO) mRNA, and suppressed TPO-promoter activity. The target of $\beta$-catenin suppressive action was a consensus $\mathrm{T}$ cell factor/lymphoid enhancing factor (TCF/LEF)-binding site $5^{\prime}$-A/T A/T CAAAG- $3^{\prime},-137$ to $-129 \mathrm{bp}$ on the rat TPO promoter. $\beta$-Catenin overexpression significantly increased complex formation between $\beta$-catenin/TCF-1 and an oligonucleotide containing the TCF/LEF
\end{abstract}

sequence, suggesting that the $\beta$-catenin/TCF- 1 complex acts as a transcriptional repressor of the TPO gene. Stable overexpression of Wnt-1 in FRTL-5 cells significantly increased the growth rate without increasing $\beta$-catenin levels. Increased growth was blunted by a PKC inhibitor, staurosporin. Wnt-1 overexpression increased serine phosphorylation, without affecting tyrosine phosphorylation, of signal transducers and activators of transcription 3 (STAT3) protein. In addition, these final results suggest that TSH-induced increase in Wnt-1 levels in thyrocytes contributes to enhanced cellular growth via a PKC pathway that increases STAT3 serine phosphorylation and activation, whereas TSH-induced decrease in activation of $\beta$ catenin simultaneously relieves transcriptional suppression of TPO. We hypothesize that Wnt signaling contributes to the ability of TSH to simultaneously increase cell growth and functional, thyroid-specific, gene expression.

Journal of Endocrinology (2007) 193, 93-106

\section{Introduction}

Wnt proteins are major signaling molecules involved in embryonic induction, generation of cell polarity, and cell fate decisions, as evidenced in studies with C. elegans, Drosophila, and mice (Cadigan \& Nusse 1997). Over the past two decades, the 19 members of the Wnt protein family that have been found in mammals, have all been shown to be cysteinerich glycoproteins that act as short-range ligands to i) locally activate receptor-mediated signaling pathways in a spatially restricted, yet dynamic expression pattern, both in embryos and adults, and ii) to be powerful regulators of cell proliferation and differentiation (Moon et al. 2004). A central player in Wnt-signaling pathways is $\beta$-catenin (Nelson \& Nusse 2004). $\beta$-Catenin, a transcription cofactor that acts together with $\mathrm{T}$ cell factor/lymphoid enhancing factor (TCF/LEF) to induce target gene expression (Cadigan \&
Nusse 1997), is a structural adaptor protein linking cadherins to the actin cytoskeleton in cell-to-cell adhesion (Gumbiner 2000, Jamora \& Fuchs 2002).

Upon secretion from cells, Wnt ligands bind to two receptor molecules: frizzled proteins and lipoprotein-related protein 5 and 6 . The binding activates multiple signaling pathways including the 'Wnt/ $\beta$-catenin' pathway, the 'Wnt/Ca ${ }^{++}$, pathway and the 'planar cell polarity' pathway (Cadigan \& Nusse 1997, Miller et al. 1999, Moon et al. 2004, Nelson \& Nusse 2004). Amongst these, the best known and most extensively studied is the 'Wnt/ $\beta$-catenin' pathway, often termed the 'canonical Wnt pathway', which regulates the cellular level of $\beta$-catenin. In the absence of Wnt signaling, $\beta$-catenin levels are low due to proteasome-mediated degradation. The $\beta$-catenin is targeted for ubiquitination and degradation in the $26 \mathrm{~S}$ proteasome by paired phosphorylation through the serine/threonine kinases, casein kinase I, and 


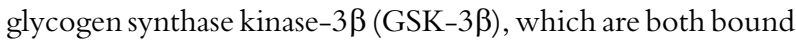
to a scaffolding complex of axin and adenomatous polyposis coli protein (Polakis 2000, 2002). Activation of Wnt signaling decreases GSK-3 $\beta$-mediated phosphorylation of $\beta$-catenin. This results in the accumulation of cytoplasmic $\beta$-catenin, which can bind the TCF/LEF transcription factors and induce the transcription of multiple target genes. The transcription of c-myc and cyclin D1, two target genes of $\beta$-catenin, which are linked to growth, is increased by $\beta$-catenin in colon cancer cells (Behrens et al. 1996, Tetsu \& McCormick 1999). Wnt signaling can also trigger the ' $\mathrm{Wnt} / \mathrm{Ca}^{++}$' pathway, which activates $\mathrm{Ca}^{++}$release and protein kinase C (PKC; Miller $e$ t al. 1999). How each pathway is preferentially activated is not clear, although the subtype of frizzled protein receptor expressed on the cell may be the main determinant (Sheldahl et al. 1999).

Knowledge of Wnt $/ \beta$-catenin signaling is important for understanding pathologic cellular growth such as cancer (Polakis 2000). Indeed, activation of the canonical Wntsignaling pathway has been observed in several types of cancers (Polakis 1997, Morin 1999, Clevers 2000, Webster et al. 2000). Additionally, mutations in the $\beta$-catenin gene $(C T N N b 1)$, which affects serine and threonine residues that are essential for the targeted degradation of $\beta$-catenin, have been observed in a wide variety of human cancers, as well as in chemically or genetically induced animal tumors (Polakis 2000). In contrast, little is known about the role of noncanonical Wnt $/ \mathrm{Ca}^{++}$-signaling pathway in pathological or physiological cell growth.

Components of the $\mathrm{Wnt} / \beta$-catenin-signaling pathway, i.e. multiple Wnt, Frizzled and the signaling adaptor, Disheveled have been shown to be expressed in human thyroid cells (Helmbrecht et al. 2001). Moreover, several studies have demonstrated dysregulation of $\mathrm{Wnt} / \beta$-catenin pathway in thyroid neoplasms exhibiting both abnormal growth and loss of thyrocyte function (Cerrato et al. 1998, Garcia-Rostan et al. 1999, 2001, Huang et al. 1999). These observations suggest that the $\mathrm{Wnt} / \beta$-catenin-signaling pathway may be involved in the physiologic and pathologic control of thyroid cell growth and function; however, the biological role of the $\mathrm{Wnt} / \beta$-catenin-signaling pathway is currently not known in normal thyrocytes.

FRTL-5 cells are a continuously growing rat thyroid cell line and have a differentiated phenotype, since they express thyroid-specific or restricted genes, such as the thyroperoxidase (TPO), thyroglobulin (Tg), sodium iodide symporter, and the thyroid-stimulating hormone receptor (TSHR) genes, all of which are under the regulatory control of TSH and insulin/insulin-like growth factor-I (IGF-I). Moreover, the growth of FRTL-5 cells is regulated by several hormones including TSH, insulin and/or IGF-I (Bidey et al. 1988, Kohn et al. 1989). Importantly, FRTL-5 cells do not exhibit characteristics of tumor cells in vitro or when transplanted in vivo.

In this study, we used the FRTL- 5 cells to evaluate the biological role of Wnt-signaling pathways in thyrocytes. We found that Wnt-1 is expressed in FRTL-5 cells and upregulated by TSH, whereas active $\beta$ catenin $(\mathrm{ABC})$ is downregulated by TSH. Transiently and stable overexpressing of Wnt-1 and $\beta$-catenin revealed unexpectedly that i) activation of the Wnt-1 ligand/receptor pathway can enhance cellular growth through a noncanonical signal involving PKC and increased serine phosphorylation of signal transducers and activators of transcription 3 (STAT3), whereas ii) activation of the canonical $\beta$-catenin pathway suppresses transcription of the TPO gene via its interaction with TCF/LEF-binding site upstream of the thyroid transcription factor (TTF)-1, Pax-8, and TTF- 2 sites on the rat TPO promoter. We hypothesize that TSH-induced increase in Wnt-1 may be important for upregulation of a noncAMP-mediated thyroid growth signal. The coincident and surprising TSH-induced decrease in $\beta$-catenin levels may result in relief of $\beta$-catenin-mediated suppression of at least one critical functional gene, the TPO gene, needed for iodination of Tg.

\section{Materials and Methods}

\section{Reagents and chemicals}

NuPAGE Novex Bis-Tris gel, nitrocellulose membrane, MagicMark XP Western Protein Standard, NuPAGE MOPS SDS Running buffer $(\times 20)$, NuPAGE Transfer buffer $(\times 20)$, NuPAGE antioxidant, NuPAGE sample reducing agent, NuPAGE LDS sample buffer $(X 4)$ were from Invitrogen Co. QuickHyb solution and sonicated salmon sperm DNA were from Stratagene Co. (La Jolla, CA, USA). Thirty percent acrylamide/bis solution and $N, N, N^{\prime}, N^{\prime}$-tetramethylethylenediamine were from Bio-Rad Laboratories Inc. Synthetic oligonucleotides were obtained from BioSynthesis Inc. (Lewisville, TX, USA). All other chemicals or reagents were from Sigma Chemical Co.

\section{Expression vectors and reporter genes}

Empty expression vector (pCS2+), mouse Wnt-1 cDNA cloned into $\mathrm{pCS} 2+(\mathrm{Wnt}-1 / \mathrm{CS} 2+)$, human $\beta$-catenin cDNA with myc tag sequence in pCS2+MT vector (MT $\beta$ Cat), human $\beta$-catenin cDNA with TAP tag sequence in pIRES PURO vector ( $\beta$ Cat), mouse Wnt-1 cDNA cloned into pVITRO3-mcs (pVITRO3/Wnt-1) have been previously described (McMahon \& Moon 1989, Yang-Snyder et al. 1996, Yost et al. 1996, Emami et al. 2004). Since pVITRO3-mcs has the hygromycin-resistance gene (hph), pVITRO3/Wnt-1 was used for making stable transfectants with FRTL- 5 cells. Control vector for $\beta$ Cat (pIRES-PURO) was made by cutting out the $\beta$-catenin cDNA fragment with EcoRV/BamHI and by re-ligation of vector fragment. Similarly, the control vector for pVITRO3/Wnt-1 (pVITRO3) was made by cutting out the Wnt-1 cDNA fragment by EcoRI and by re-ligation of vector fragment. Human TPO-promoter-luciferase constructs of various lengths from the transcription start site (pSV0/TPO-181 
pSV/TPO-1372 pSV/TPO-6300 pSV) have been previously described (Kikkawa et al. 1990, Mizuno et al. 1991, Suzuki et al. 1998). SuperTOPFlash reporter, luciferase reporter vector containing multiple TCF/LEF-binding sites and its negative control vector SuperFOP vector were previously described (Kaykas et al. 2004).

\section{Cell culture and establishment of stably transfected cell lines}

The F1 subclone of FRTL-5 rat thyroid cells (Interthyr Research Foundation, Baltimore, MD, USA) was grown in Coon's modified F-12 medium supplemented with 5\% heat inactivated calf serum, $1 \mathrm{mM}$ nonessential amino acid, and a mixture of six hormones (6H) including TSH, insulin, cortisol, transferrin, glycyl-L-histidyl-L-lysine acetate, and somatostatin (Shimura et al. 1994, Saji et al. 1997). In some experiments, FRTL-5 cells were fed $5 \mathrm{H}$ medium (i.e. $6 \mathrm{H}$ medium without TSH) for 5-6 days prior to the day of the experiment.

FRTL-5 cells stably overexpressing Wnt-1 protein were established using the electroporation method. Briefly, FRTL5 cells grown in $6 \mathrm{H}$ media were harvested. Mammalian expression vector for Wnt-1 (pVITRO3/Wnt-1) or empty vector (pVITRO3) were prepared and cell suspension $(10 \times$ $10^{6} \mathrm{cells} / \mathrm{ml}$ ) was mixed with $30 \mu \mathrm{g}$ plasmid in a cuvette and electroporated at $300 \mathrm{~V}$ (capacitance at $960 \mu \mathrm{F}$ ) using Gene Pulser (Bio-Rad Laboratories). Individual clones were selected and maintained in the presence of $200 \mu \mathrm{g} / \mathrm{ml}$ hygromycin B (Invitrogen). Clones were screened and selected based on Wnt-1 expression level.

\section{Transient transfection of FRTL-5 cells}

Transient transfection of Fischer rat thyroid cells in low serum, chronically expressed to $5 \%$ serum (FRTL-5) cells was carried out using DEAE-dextran (ProFection Mammalian Transfection System, Promega) according to the manufacturer's instruction. Briefly, cells were grown in $6 \mathrm{H}$ medium until $40-50 \%$ confluency and subsequently maintained in $5 \mathrm{H}$ medium for 5-6 days. A day prior to transfection, the cells were again fed with $6 \mathrm{H}$ medium. Twenty micrograms plasmid were used for an transfection of 1 dish of cells. After transfection, cells were grown in $6 \mathrm{H}$ medium for an additional $48-72 \mathrm{~h}$ to be harvested for total RNA or cell lysate preparation.

$\mathrm{LiCl}$ is a known GSK-3 inhibitor (Klein \& Melton 1996) which leads to accumulation of $\beta$-catenin in cells. The optimal concentration of $\mathrm{LiCl}$ for inducing $\beta$-catenin accumulation was $2 \mathrm{mM}$ (data not shown); concentrations higher than $2 \mathrm{mM}$ were cytotoxic (data not shown).

\section{Luciferase assay}

The effects of $\beta$-catenin or Wnt-1 overexpression on TPOpromoter activities were evaluated using luciferase assay. FRTL-5 cells were transfected with 100 ng various TPO-promoter-luciferase constructs (pSV0/TPO-181 pSV/TPO-1372
$\mathrm{pSV} / \mathrm{TPO}-6300 \mathrm{pSV}$ ) and $1 \mu \mathrm{g} \beta$-catenin or Wnt-1 expression vector using DEAE-dextran solution. Cells were lysed after $48 \mathrm{~h}$, and luciferase activity was measured using luciferase assay system (Promega) and a LUMAT LB 9507 luminometer (Berthold GmbH \& Co. KG, Bad Wildbad, Germany). Data presented were normalized to protein concentration of cell lysate.

\section{Western blot analysis}

Cells were lysed in lysis buffer (50 mM Tris- $\mathrm{HCl}(\mathrm{pH} 8 \cdot 0)$, $150 \mathrm{mM} \mathrm{NaCl}$, and protease inhibitor cocktail (EMD Biosciences Inc. San Diego, CA, USA)). The lysate was sheared by sonic dismembrator and quantified using micro bicinchoninic acid (BCA) protein assay kit (Pierce, Rockford, IL, USA). Twenty micrograms lysate were resolved on NuPAGE Bis-Tris gel (Invitrogen) and transferred to nitrocellulose membrane. Membranes were immunoblotted with specific antibodies and revealed using enhanced chemiluminescent (ECL) western blot detecting system (Amersham Biosciences). The antibodies were against $\beta$-catenin (7963, Santa Cruz Biotechnology Inc., Santa Cruz, CA, USA), ABC (05-665, Upstate Biotechnology Inc., Lake Placid, NY, USA), total STAT3 (06-596, Upstate Biotechnology Inc.), STAT3 phosphorylated on Tyr705 (9131S, Cell Signaling Technology, Beverly, MA, USA), STAT3 phosphorylated on Ser727 (44-384G, Biosource International Inc., Camarillo, CA, USA), Wnt-1 (36-5800, Zymed Laboratories Inc., South San Francisco, CA, USA), or $\beta$-actin (4967, Cell Signaling Technology). ABC antibodies recognize $\beta$-catenin, which is dephosphorylated on Ser37 and Thr41 (van Noort et al. 2002).

\section{$R N A$ isolation and northern blot analysis}

Northern blot analysis was performed as previously described (Suzuki et al. 1999). Twelve micrograms total RNA per lane were resolved in $1 \%$ denaturing agarose gels containing 0.66 M formaldehyde and transferred onto Nytran membranes, UV cross-linked and hybridized with specific probes. The probes for rat Tg, TPO, TSHR (Isozaki et al. 1989, Fabbro et al. 1994, Shimura et al. 1994, Saji et al. 1997, Suzuki et al. 1998), and glyceraldehyde-3-phosphate dehydrogenase (GAPDH) have been described (Suzuki et al. 1999). The probe for Wnt-1 was obtained from mouse Wnt-1 expression vector. Probes were labeled with $\alpha_{-}{ }^{32} \mathrm{P}-\mathrm{dCTP}$ using the Ladderman Labeling Kit (Takara Biochemical Inc.; Berkeley, CA, USA). Northern blots were developed using a BAS 1500 Bioimaging Analyzer (Fuji Photo Film Co. Ltd Medical Systems USA Inc., Stamford, CT, USA).

\section{Nuclear extracts and electrophoretic mobility shift assay (EMSA)}

Nuclear extracts were prepared from harvested FRTL-5 cells using NE-PER nuclear and cytoplasmic extraction reagents (Pierce) in the presence of a protease inhibitor cocktail 
(phenylmethylsulfonyl fluoride, Leupeptin, Pepstatin-A). Double-stranded DNA corresponding to bases -145 out of - 123 of the rat TPO-promoter (Francis-Lang et al. 1992) was end labeled with $\left[\gamma_{-}{ }^{32} \mathrm{P}\right]$ ATP using T4 polynucleotide kinase. Binding reaction for TCF/LEF EMSA (30 min, room temperature) included ${ }^{32} \mathrm{P}$-labeled probe (activity $100000 \mathrm{cpm}), 10 \mu \mathrm{g} \mathrm{NE}$ of Wnt-1/ $\beta$-catenin-transfected cells, $0.05 \mu \mathrm{g}$ poly (dI-dC), $2 \mathrm{mM}$ DTT, 2.5\% glycerol, 0.05\% NP-40, 40 mM Tris- $\mathrm{HCl}$ (pH 7.5), $200 \mathrm{mM} \mathrm{NaCl}$, and $5 \mathrm{mM} \mathrm{MgCl}_{2}$. After the incubations, reaction mixtures were electrophoresed on $5 \%$ native polyacrylamide gels and autoradiographed. The DNA sequence of the oligonucleotide used as DNA probe (top strand only) for TCF/LEF-binding site on rat TPO-promoter was $5^{\prime}$-AGTGGCACCTTTGTTCTGACCAG-3' ${ }^{\prime}$. Antibody specific for TCF-1 was from Santa Cruz Biotechnology Inc.

\section{Cell growth assay}

Cell growth was measured using (3-(4, 5-dimethylthiazolyl-2)2, 5-diphenyltetrazolium bromide) (MTT) assay (Mosmann 1983). Cells were plated at $2 \times 10^{4}$ cells/well in 24 -well plates and incubated for the indicated times. At each time period, $50 \mu \mathrm{l}$ $1 \mathrm{mg} / \mathrm{ml} \mathrm{MTT}$ solution were added to each well with $3 \mathrm{~h}$ incubation and $500 \mu \mathrm{l} 10 \%$ Triton-X in isopropyl alcohol was added to dissolve the converted dye. The absorbance of solution from each well was measured at $570 \mathrm{~nm}$. Value measured $3 \mathrm{~h}$ after plating was considered as baseline.

\section{Flow cytometric analysis of cell cycle}

Cells at 80-90\% confluency were harvested, washed, and resuspended in PBS; ice-cold ethanol was added to the cell suspensions. Samples were stored at $4{ }^{\circ} \mathrm{C}$ until the day of

analysis. On the day of analysis, samples were washed and incubated with PBS solution containing ribonuclease A $(3 \mu \mathrm{g} / \mathrm{ml})$ and propidium iodide $(0.05 \mathrm{mg} / \mathrm{ml})$ for $15 \mathrm{~min}$ at $37^{\circ} \mathrm{C}$ in dark. Cells were analyzed using a FACSort flow cytometer (Becton Dickinson, San Jose, CA, USA). The area of the red fluorescence voltage pulse for the cells is proportional to its DNA content.

\section{Statistical analysis}

Mann-Whitney $U$ test (SPSS 13.0; SPSS Inc., Chicago, IL, USA) was used to assess statistical differences between two groups. Unless stated otherwise, all error bars represent S.D.

\section{Results}

TSH increases endogenous Wnt-1 expression, but decreases ABC levels, in FRTL-5 thyroid cells

Initially, we investigated the basal expression and the effects of TSH on expression of selected Wnts in FRTL-5 thyroid cells. FRTL-5 thyrocytes were cultured in the presence or absence of TSH. Subsequently, the mRNA and the protein levels of Wnts were assessed using northern- and western blot analyses. As shown in Fig. 1, Wnt-1 mRNA (Fig. 1a) and protein levels (Fig. 1b) in FRTL-5 thyrocytes were significantly increased in the presence of TSH ( + TSH lane). In contrast, Wnt-5a expression levels were not significantly affected by the presence of TSH (data not shown). Of note, FRTL-5 cells did not express WnT-3a (data not shown). Thus, TSH appears to specifically upregulate Wnt-1 levels in FRTL-5 cells.

Wnt-1 is known to increase the intracellular amount of $\beta$-catenin through the inhibition of its degradation (Cadigan

\section{(b) Western blot}

(a) Northern blot

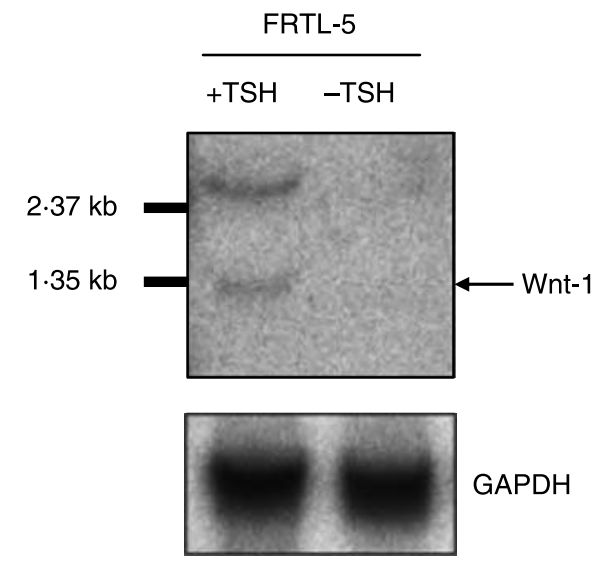

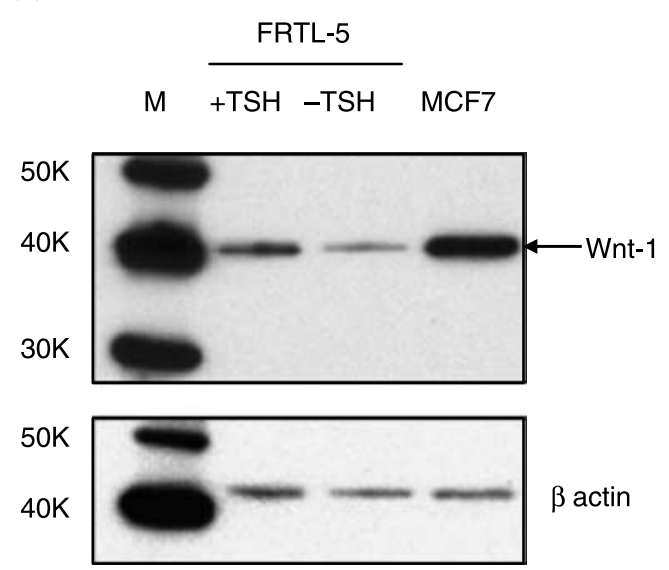

Figure 1 TSH increases endogenous Wnt-1 expression in FRTL-5 cells. FRTL-5 cells were grown in the absence $(-\mathrm{TSH})$ or presence ( $+\mathrm{TSH}$ ) of TSH for 5 days. (a) Total cellular RNA was subjected to northern blot analyses using Wnt-1 probe. (b) Twenty micrograms cell lysates were subjected to SDS-PAGE and western blot analysis using Wnt-1 antibody. $\beta$-Actin staining of blots after transfer revealed equivalent loading of total protein. MCF7, a breast cancer cell line known to overproduce Wnt-1 protein, was used as positive control. Results presented are typical of two separate experiments. 
\& Nusse 1997, Miller et al. 1999, Moon et al. 2004, Nelson \& Nusse 2004). When FRTL-5 cells were transfected with Wnt-1, Wnt-3a, or Wnt-5a expression vectors, an increase in ABC level was most prominent with Wnt-1 overexpression (Fig. 2a, lower panel, arrow). Total $\beta$-catenin was at best slightly increased only with Wnt-1 overexpression (Fig. 2a, upper panel, arrow), but the changes in total $\beta$-catenin level were less prominent than those in $\mathrm{ABC}$. As a consequence, the relative change in active relative to total $\beta$-catenin seemed clear. Given this, and our findings that TSH increased Wnt-1 levels in FRTL-5 thyrocytes (most likely through transcriptional regulation), we hypothesized that TSH would increase $\beta$-catenin levels in FRTL-5 cells. Remarkably, TSH caused a pronounced decrease in cellular ABC protein levels (Fig. 2c, arrow), and also a slight decrease in total $\beta$-catenin levels (Fig. 2b, arrow). Of note in these experiments, the lower antibody reactive complex that was detected in the western blots (Fig. 2a and c) was not dependent on Wnt1 transfection (Fig. 2a), appeared to be unique to FRTL-5 cells (data not shown), and increased with TSH treatment (Fig. 2c), whereas
$\mathrm{ABC}$ decreased. Its nature is not known but it is not associated with Wnt-1 overexpression.

The basis for these apparent paradoxical results and their biological significance are the subject of the remaining parts of this report.

Wnt-1 suppresses transcription of the TPO gene in FRTL-5 cells

To investigate the functional significance of activation of the canonical Wnt-1/ $\beta$-catenin-signaling pathway in FRTL-5 thyroid cells, we measured changes in thyroid-specific gene expression induced by overexpression of $\beta$-catenin or Wnt-1 in the FRTL- 5 thyrocytes. Transient transfection of FRTL-5 cells with a $\beta$-catenin expression vector significantly decreased the amount of TPO RNA when compared with vector (control)-transfected FRTL-5 cells (Fig. 3a and b). When LiCl, a GSK3 $\beta$ inhibitor known to increase cellular $\beta$-catenin level, was added to transfected FRTL- 5 cells, the amount of TPO RNA was further decreased (Fig. 3a and b). Decreases in TSHR RNA were also observed with

(a)

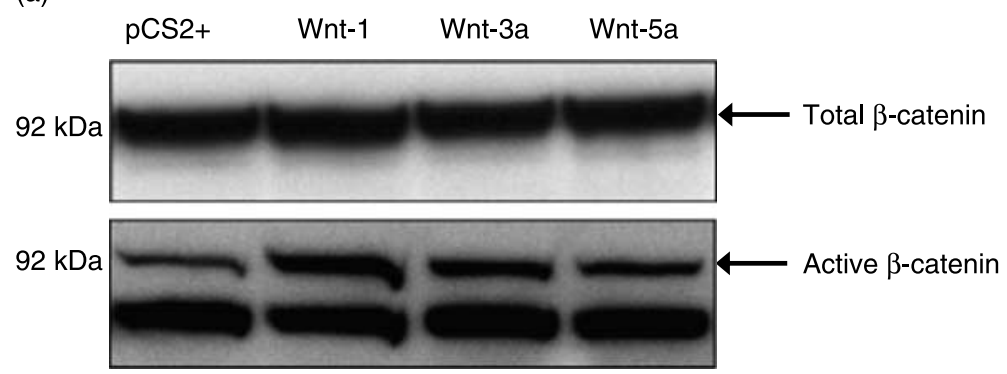

(b)

\section{$5 \mathrm{H} 5$} (-TSH)

$6 \mathrm{H} 5(+\mathrm{TSH})$

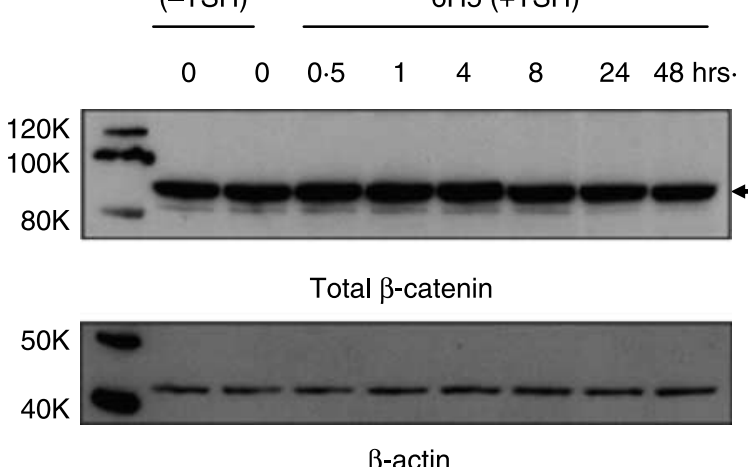

(c)

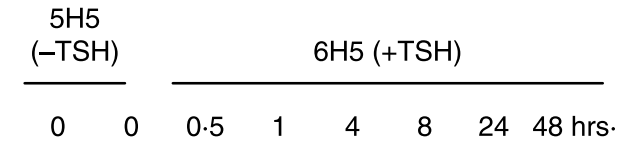

Active $\beta$-catenin

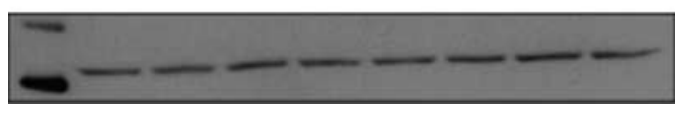

$\beta$-actin

Figure 2 TSH decreases total and active $\beta$-catenin levels in FRTL-5 cells. (a) Lysates of FRTL-5 cells transfected with Wnt-1, Wnt-3a or Wnt-5a expression vectors were subjected to SDS-PAGE and western blot analysis using antibody against total $\beta$-catenin (upper panel) or against 'active $\beta$-catenin' (lower panel). $\beta$-Actin staining of blots after transfer revealed equivalent loading of total protein (data not shown). (b) Lysates of FRTL-5 cells grown in the absence $(-\mathrm{TSH})$ or presence $(+\mathrm{TSH})$ of TSH were subjected to SDS-PAGE and western blot analysis using antibody against total $\beta$-catenin. (c) Lysates of FRTL-5 cells grown in the absence $(-\mathrm{TSH})$ or presence $(+\mathrm{TSH})$ of TSH were subjected to SDS-PAGE and western blot analysis using antibody against active $\beta$-catenin. After maintenance of cells in the absence of TSH for several days, TSH was added at each indicated time $(0 \cdot 5,1,4,8,24,48 \mathrm{~h}$; before harvesting cells) and all were harvested simultaneously in experiment (b) \& (c). $\beta$-Actin staining of blots after transfer revealed equivalent loading of total protein. Arrows indicate target protein (total or active $\beta$-catenin). Results presented are typical of two separate experiments. 
(a)

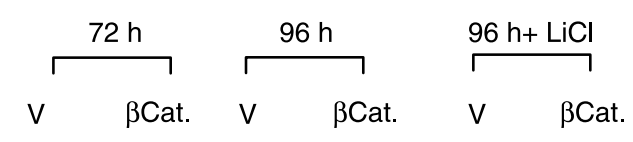

rTPO

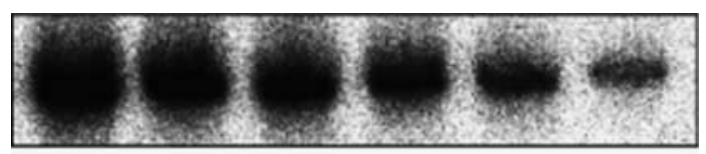

rTSHR

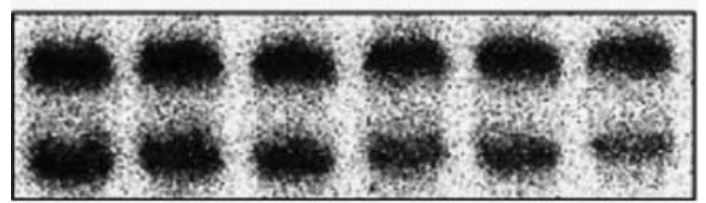

$\mathrm{rTg}$

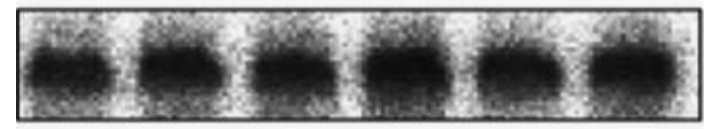

GAPDH

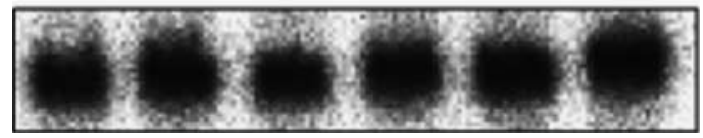

(b)

(c)
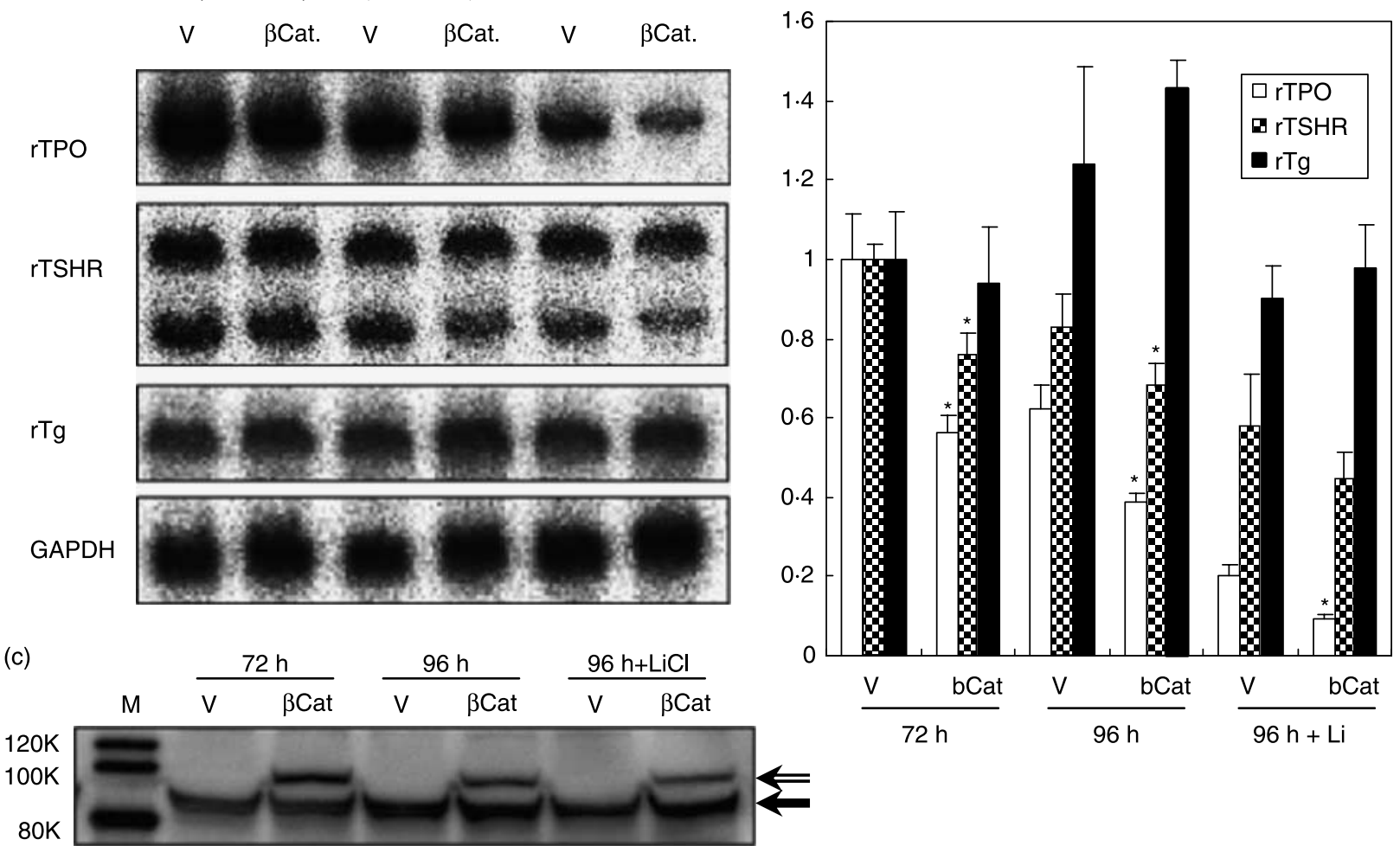

Figure 3 Transient transfection of FRTL-5 cells with $\beta$-catenin significantly decreases TPO RNA, has a modest effect on TSHR RNA and no effect on Tg RNA. (a) Total cellular RNA from $\beta$-catenin ( $\beta$ Cat) or vector $(V)$ transfected FRTL- 5 cells was subjected to northern blot analyses using appropriate probes for TPO, TSHR, and Tg. GAPDH probe was used as the loading control. In certain experiments, LiCl was added to the medium to augment the increases in $\beta$-catenin levels. Results presented are typical of three separate experiments. (b) RNA levels were quantified using BAS 1500 Bioimaging Analyzer. RNA levels were normalized to respective GAPDH controls. All values are means \pm s.D. of three separate experiments. Asterisks $\left(^{*}\right)$ denote significance $(P<0 \cdot 05)$ in relative to vector control. (C) Lysates of FRTL-5 cells transfected with $\beta$-catenin expression vector $(\beta C$ at) or control vector $(V)$ were subjected to SDS-PAGE and western blot analysis using antibody against total $\beta$-catenin. Upper bands (white arrow) represent bigger $\beta$-catenin protein produced by $\beta$-catenin transfection and lower bands (black arrow) represent endogenous $\beta$-catenin.

overexpression of $\beta$-catenin (about $20 \%$, Fig. 3a and b), but were less prominent than TPO RNA. Of note, Tg RNA levels were not affected by overexpression of $\beta$-catenin or by $\mathrm{LiCl}$ (Fig. 3a and b). The decrease in TPO RNA in $\beta$-catenin-transfected cells was statistically significant in each replicate experiment $(P<0 \cdot 05)$. The overexpression of $\beta$-catenin was confirmed by western blot for total $\beta$-catenin in transfected FRTL-5 cells (Fig. 3c).

Transient transfection of FRTL-5 cells with Wnt-1 expression vector (which increases ABC levels (Fig. 2a)) also decreased TPO RNA when compared with vector (control)transfected cells (about 30\%, Fig. 4, lane 2 vs lane 1). This suppressive effect was evident in the presence or absence of TSH (Fig. 4, lanes 2 vs 1 and lanes 6 vs 5 respectively). LiCl added to transfected FRTL- 5 cells further decreased the amount of TPO RNA. RNA levels of TSHR and Tg were not affected by overexpression of Wnt-1 (data not shown). In all experiments, the efficacy of $\mathrm{LiCl}$ treatment was verified by confirming increases in the amount of total and 'active' $\beta$-catenin in LiCl-treated FRTL-5 cells (data not shown).

To probe whether Wnt- $1 / \beta$-catenin act transcriptionally to inhibit TPO gene expression and also to get an idea of the molecular mechanism of Wnt- $1 / \beta$-catenin's inhibitory action, we conducted TPO-promoter reporter assays. In an attempt to grossly separate their activities, three truncations of the human TPO transcriptional regulatory element were created: constructs of 181,1372 , and $6300 \mathrm{bp}$ of $5^{\prime}$-flanking region (TPO-181 pSV, TPO-1372 pSV, and TPO-6300 pSV respectively). These were then inserted into a luciferase reporter plasmid and transfected into Wnt- $1 / \beta$-catenintransfected FRTL-5 cells and vector-transfected cells. Wnt-1 or $\beta$-catenin overexpression significantly decreased the promoter activities of all three constructs compared with that of vector-transfected cells (Fig. 5). Moreover, the suppressive effects were observed both in the presence of TSH (Fig. 5a, 6H condition) or the absence of TSH (Fig. 5b, 
(a)

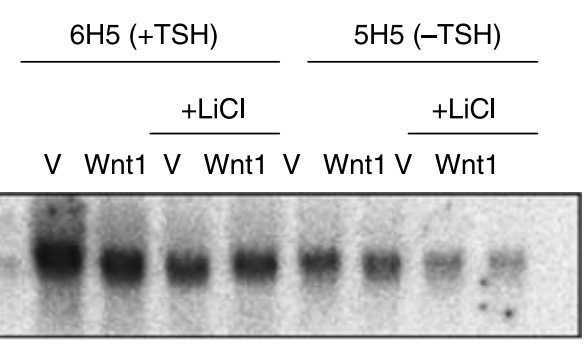

GAPDH

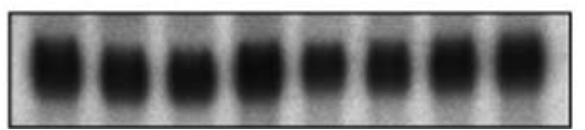

(b)

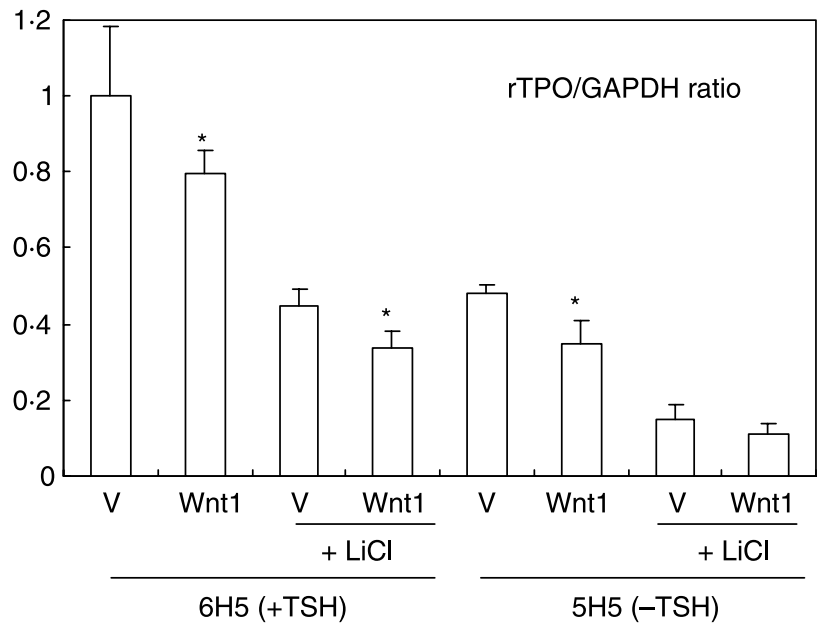

Figure 4 Transient transfection of FRTL-5 cells with Wnt-1 significantly decreases TPO RNA. (a) Total cellular RNA from Wnt-1 (Wnt1) or vector $(\mathrm{V})$ transfected FRTL-5 cells was subjected to northern blot analyses using appropriate probes for TPO. GAPDH probe was used as the loading control. Cells were grown in the absence $(-\mathrm{TSH})$ or presence $(+\mathrm{TSH})$ of TSH for $48 \mathrm{~h}$ after transfection. In certain experiments, $\mathrm{LiCl}$ was added to the medium to augment the increases in $\beta$-catenin levels. Results presented are representative of three separate experiments. (b) RNA levels were quantified using northern blot images and BAS 1500 Bioimaging Analyzer. RNA levels were normalized to respective GAPDH controls. All values are means \pm s.D. of three separate experiments.

$5 \mathrm{H}$ condition). Stimulation of $\beta$-catenin signaling by Wnt-1 or $\beta$-catenin overexpression in FRTL- 5 cells was confirmed by observing significant increase in luciferase activity of the SuperTOPFlash reporter, containing multiple TCF/LEFbinding sites in separate experiments (data not shown). In addition, these data clearly demonstrate that Wnt-1/ $\beta$-catenin act to inhibit TPO gene expression and suggest that Wnt- $1 / \beta$-catenin act on a transcriptional regulatory event that occurs within $181 \mathrm{bp}$ of the $5^{\prime}$-flanking region of the TPO gene.

The locations of multiple cis elements known to play a role in TPO expression, TTF-1, Pax-8, and TTF- 2 lie within the 181 bp 5'-flanking region (Fig. 6a; Francis-Lang et al. 1992, Zannini et al. 1992, Aza-Blanc et al. 1993, Ortiz et al. 1999). We first sought to determine whether the suppressive effect of Wnt- $1 / \beta$-catenin was a consequence of Wnt- $1 / \beta$-catenin inhibition of these thyroid-specific transcription factors. The western blot analyses and EMSAs revealed that Wnt-1 or $\beta$-catenin overexpression neither affected the amount of TTF-1, Pax-8, or TTF-2 protein nor did they affect the DNAbinding affinity of TTF-1, Pax-8 or TTF-2 (data not shown).

Since luciferase reporter assays suggested that Wnt-1/ $\beta$-catenin affect a transcriptional regulatory event that occurs within $181 \mathrm{bp}$ of the $5^{\prime}$-flanking region of the TPO gene (Fig. 5) and EMSAs demonstrated that Wnt- $1 / \beta$-catenin did not affect TTF-1, TTF-2 and Pax-8 (data not shown), we considered the possibility that the TPO gene might be a target for transcriptional suppression by some other mechanism. The sequence 'CTTTGTT', which is complementary to a core TCF/LEF-binding site $5^{\prime}$-A/T A/T CAAAG- $3^{\prime}$, lies within the $181 \mathrm{bp} 5^{\prime}$-flanking region of the rat TPO-promoter (between -137 and -129 bp, Fig. 6a; van de Wetering et al. 1997). To determine whether the suppressive effect of Wnt-1/ $\beta$-catenin was a consequence of Wnt-1/ $\beta$-catenin effect on the $\beta$-catenin/TCF complex, we conducted EMSA (Fig. 6b). EMSAs were performed using an oligo-nucleotide including
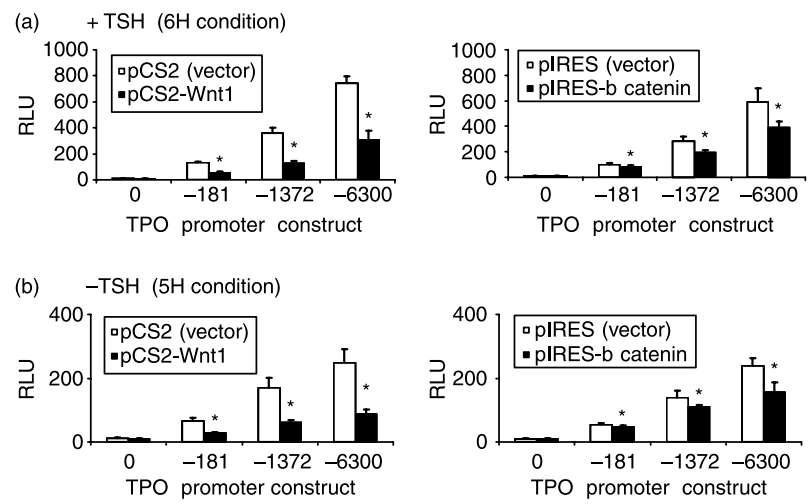

Figure $5 \beta$-Catenin and Wnt-1 overexpression suppresses TPO promoter activity in FRTL-5 cells. FRTL-5 cells were transfected (using the DEAE-dextran solution) with $100 \mathrm{ng}$ various TPOpromoter-luciferase constructs (pSV0/TPO-181 pSV/TPO-1372 pSV/TPO-6300 pSV) in the presence of $1 \mu \mathrm{g} \beta$-catenin or Wnt-1 expression vector. Subsequently, the cells were cultured with ( $+\mathrm{TSH}, 6 \mathrm{H}$ condition) or without TSH ( $-\mathrm{TSH}, 5 \mathrm{H}$ condition). Cells were lysed and luciferase activity measured using a luminometer. The values were normalized to the protein concentration of cell lysate. The luciferase activity indicated by relative light units (RLU) correlates with the level of promoter activity. All values are means \pm S.D. of six independent wells. Results presented are typical of two separate experiments. Asterisks $(*)$ denote significance $(P<0 \cdot 05)$ relative to vector control. 
the TCF/LEF-binding site sequence in the rat TPO-promoter (5'-AGTGGCACCTTTGTTCTGACCAG-3'; binding sequence underlined). As shown in Fig. $6 b$, a specific and prominent band representing a complex between $\beta$-catenin/ TCF complex and the oligonucleotide was identified, as evidenced by i) inhibition of the complex (super-shift) by antibodies to TCF-1 (lane 9, 10) or to 'ABC' (lane 11) and ii) elimination by competition with 100-fold molar excess of unlabeled DNA probe (lane 8). FRTL-5 cells transfected with two different kinds of $\beta$-catenin expression vectors (MT $\beta$ Cat and $\beta C$ at, $\beta \mathrm{Ct}$ and $\beta \mathrm{Ct}^{\prime}$ respectively) showed increased complex formation (Fig. 6b; lane 5 and 7) by comparison with their respective controls (Fig. $6 b$; lane 4 and 6 respectively). These data indicate that $\beta$-catenin overexpression causes increased DNA binding of $\beta$-catenin/TCF complex with a TCF/LEF-binding sequence on the rat
TPO-promoter, suggesting that the $\beta$-catenin/TCF complex might act as a transcriptional repressor of TPO gene. Of note, Wnt-1 overexpression had no effect on the $\beta$-catenin/TCF complex (Fig. 6b; lane 3 vs lane 2); the reason for this is unclear but may relate to the transfection efficiency and resulting minimum increases in $\beta$-catenin induced experimentally by this procedure.

Wnt-1 enhances the growth of FRTL-5 cells

We probed the effects of Wnt-1 overexpression on the growth of FRTL-5 cells. Since the transfection efficiency of FRTL-5 cells is very low, regardless of the transfection method utilized; it is difficult to observe any change in growth rate of cells by transient transfection. Accordingly, to evaluate the effect of Wnt-1 on FRTL-5 cell growth, we isolated stable cell lines

(a)

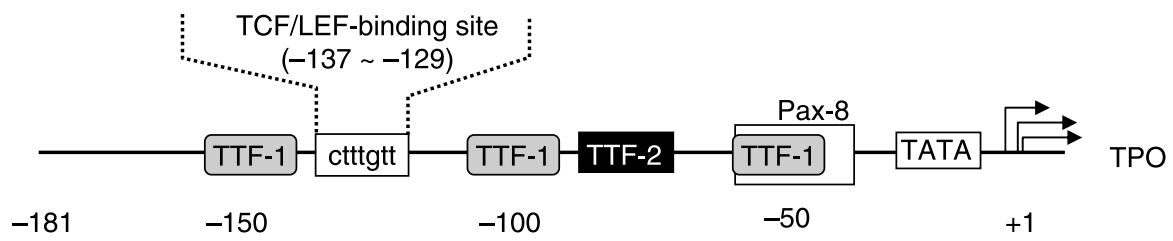

(b)

\begin{tabular}{|c|c|c|c|c|c|c|c|c|c|c|c|}
\hline NE & - & V & W1 & V & $\beta C t$ & $V^{\prime}$ & $\beta C t^{\prime}$ & $V^{\prime}$ & $V^{\prime}$ & $\beta C t^{\prime}$ & $V^{\prime}$ \\
\hline Cold probe & - & - & - & - & - & - & - & + & - & - & - \\
\hline TCF-1 Ab & - & - & - & - & - & - & - & - & + & + & - \\
\hline$A B C A b$ & - & - & - & - & - & - & - & - & - & - & + \\
\hline
\end{tabular}

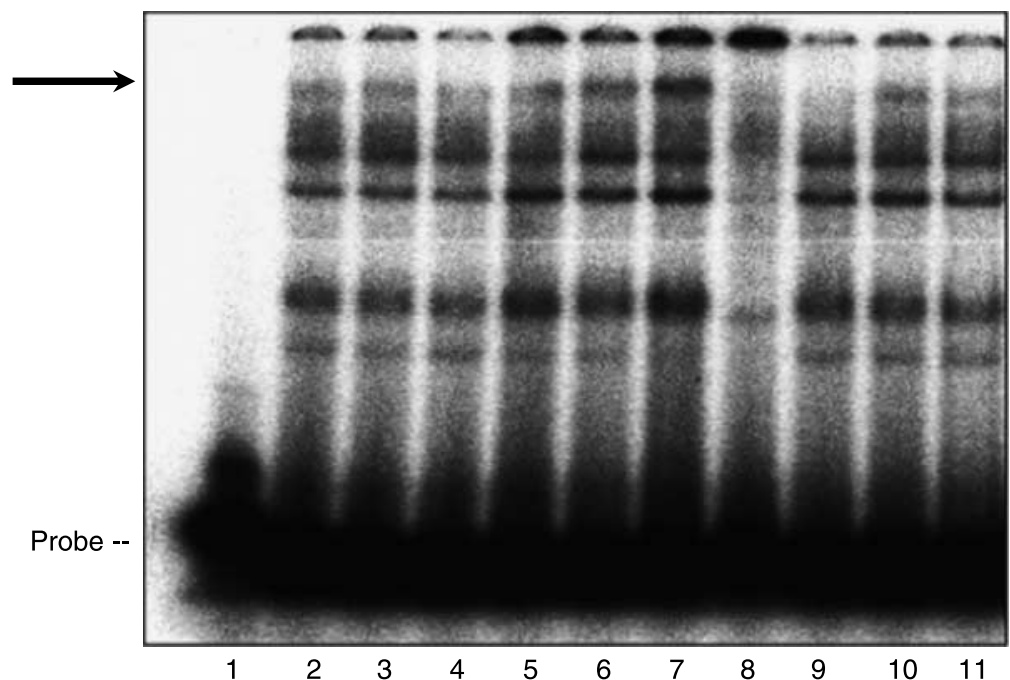

Figure $6 \beta$-Catenin overexpression increases the complex formation between $\beta$-catenin/TCF- 1 complex and cis-element of TCF/LEF-binding site on rat TPO promoter. (a) Schematic illustration of multiple cis-acting elements affecting TPO expression in $5^{\prime}$-flanking region of rat TPO gene. (b) EMSAs were performed with ${ }^{32}$ P-labeled TCF/LEF- site probe (rat TPO TCF/LEF- site: sense $5^{\prime}$-AGTGGCACCTTTGTTCTGACCAG- $3^{\prime}$ ) and $10 \mu \mathrm{g}$ NEs prepared from vector-transfected (pCS2 +, V), pCS2 +/Wnt-1-transfected (W1), MT $\beta$ Cattransfected $(\beta C t)$, pIRES-PURO-transfected $\left(V^{\prime}\right)$ and $\beta C$ at-transfected $\left(\beta C t^{\prime}\right)$ FRTL-5 cells. Results presented are typical of two separate experiments. Legend: cold probe indicates absence $(-)$ or presence $(+)$ of 100 -fold molar excess of unlabeled TCF/LEF- site probe. TCF-1 Ab indicates absence $(-)$ or presence $(+)$ of $2 \mu \mathrm{g}$ antibody to TCF-1. ABC Ab indicates absence $(-)$ or presence $(+)$ of $1.5 \mu$ g antibody to active $\beta$-catenin. 
overexpressing Wnt-1. These were isolated by transfection of Wnt-1 expression vector containing a hygromycin-resistance gene as a selection marker into FRTL-5 cells by electroporation and cell cloning. As a control, vector-transfected cell clones were also isolated. Several clones were obtained both for Wnt-1- and for vector-transfected cells; however, for growth rate studies only one representative clone from each group was selected. Clone consistently showing high Wnt-1 mRNA and high Wnt-1 protein expression was selected in Wnt-1-transfected cells, and the opposite was selected in vector-transfected cells. Wnt-1 overexpression was confirmed by northern and western blots (Fig. 7). Wnt-1 overexpressing clone (W1) had significantly higher growth rate when compared with vector-transfected clone (V3) as determined by MTT assay (Fig. 8). This enhanced growth rate of Wnt-1 overexpressing cell line was confirmed by cell-cycle analysis using flow cytometry by measuring DNA content of cells stained by propidium iodide. Notably, the percentage of cells in $\mathrm{S} / \mathrm{G} 2 / \mathrm{M}$ phase was significantly higher in Wnt-1 overexpressing clone (W1) than in vector-transfected clone (V3) both in the presence or absence of TSH (Fig. 9).

We sought to determine the mechanism of Wnt-1-induced increased growth rate of FRTL-5 cells. Cyclin D1 is known to be one of the target genes of Wnt activation because $\beta$-catenin increases the expression of cyclin D1 in colorectal cancer cell lines in vitro (Shtutman et al. 1999, Tetsu \& McCormick 1999). This forms the basis of involvement of Wnt-pathway activation in growth-promoting effect,

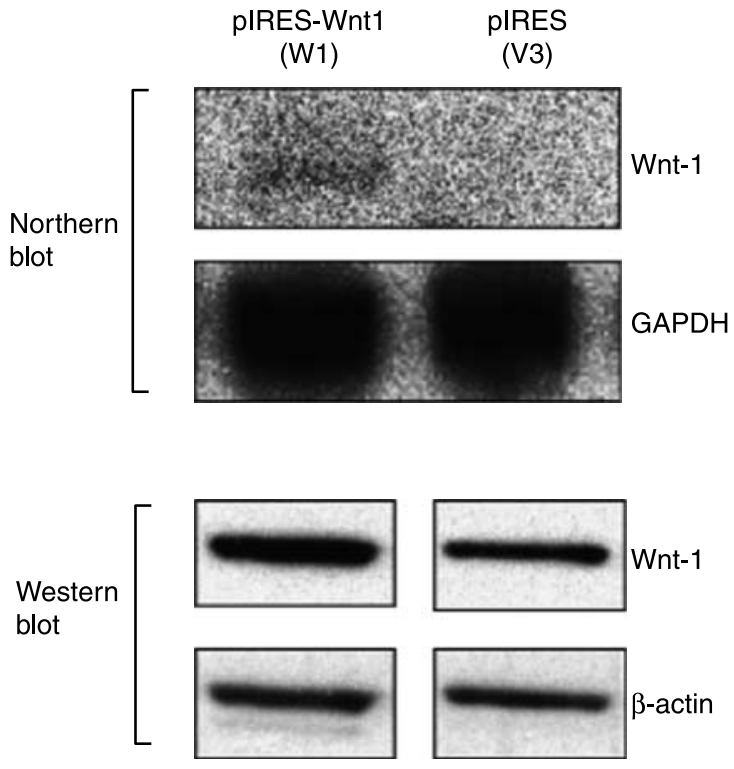

Figure 7 Stable transfection of FRTL- 5 cells with Wnt- 1 increases their Wnt-1 production. Wnt-1 RNA (upper panel) and protein level (lower panel) of FRTL-5 cells stably transfected with Wnt-1 expression vector (pIRES-Wnt1) or control vector (pIRES) were compared by northern and western blots respectively. Representative clones from Wnt-1 overexpressing cells (W1) and vectortransfected cells (V3) were selected for comparison.

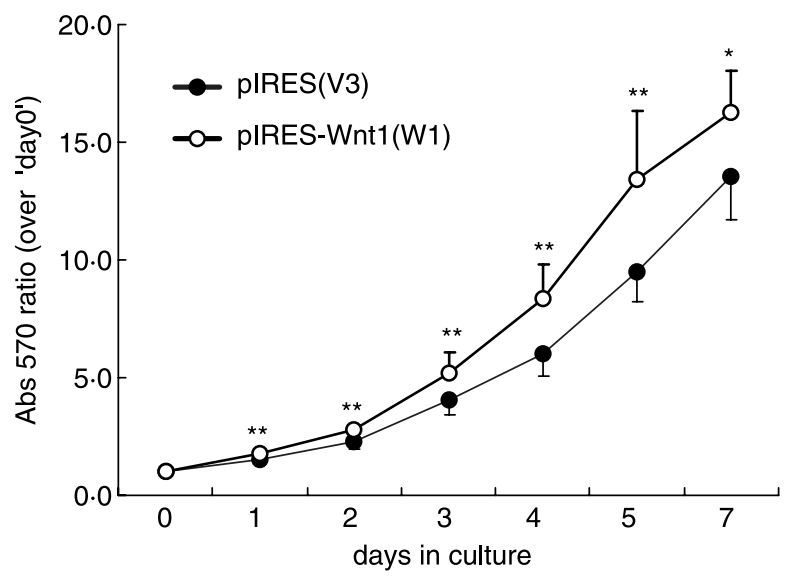

Figure 8 Stable transfection of FRTL-5 cells with Wnt-1 increases their growth rate. Growth rates of FRTL- 5 cells stably transfected with Wnt-1 expression vector ( $p$ IRES-Wnt1) or control vector ( $p$ IRES) were compared at indicated time points using MTT assay. Representative clones from Wnt-1 overexpressing cells (W1) and vector-transfected cells (V3) were selected for comparison. Cells were grown in the presence of TSH (6H5 media). Background absorbance (cell culture medium only) was subtracted to obtain actual absorbance. Absorbance values are plotted relative to baseline absorbance (i.e. absorbance at day 0 ). All values are mean \pm s.D. of six independent wells. *Indicates $P<0 \cdot 01,{ }^{* *}$ indicates $P<0 \cdot 05$. Results presented are typical of two separate experiments.

especially in colon cancer cells (Polakis 2000). However, total $\beta$-catenin levels were unchanged in Wnt-1 overexpressing clone (W1) as compared with vector-transfected clone (V3; data not shown); this was evidenced in multiple experiments. Interestingly, the levels of 'ABC' (nonphosphorylated Ser-37 and Thr-41 form (van Noort et al. 2002) forming nuclear complex with TCF/LEF factors) were not different between Wnt-1 overexpressing clone (W1) and vector-transfected clone (V3; data not shown). Taken together, these data suggest that the Wnt-1-induced increased growth rate is not regulated by the canonical 'Wnt/ $\beta$-catenin' pathway. In addition, level of TPO mRNA was not different between W1 and V3 clone (data not shown).

Besides, activating $\beta$-catenin, some Wnt proteins can also increase intracellular $\mathrm{Ca}^{2+}$ and subsequently activate PKC in some contexts (Miller et al. 1999, Sheldahl et al. 1999, Kremenevskaja et al. 2005). To determine if PKC is involved in the growth-promoting effect, we investigated the effects of staurosporin, a PKC inhibitor, on the growth of Wnt-1 overexpressing clone (W1). Wnt-1 overexpressing clone (W1) had a significantly higher growth rate than the vectortransfected clone (V3; Fig. 10). However, in the presence of staurosporin, the growth rate of Wnt-1 overexpressing clone (W1) was significantly blunted when compared with vectortransfected clone (V3; Fig. 10). Moreover, the STAT3 phosphorylation on the serine 727 residue (one of the downstream effects of PKC activation), but not on the tyrosine 705 residue, was increased in Wnt-1 overexpressing clone (W1) when compared with vector-transfected clone 

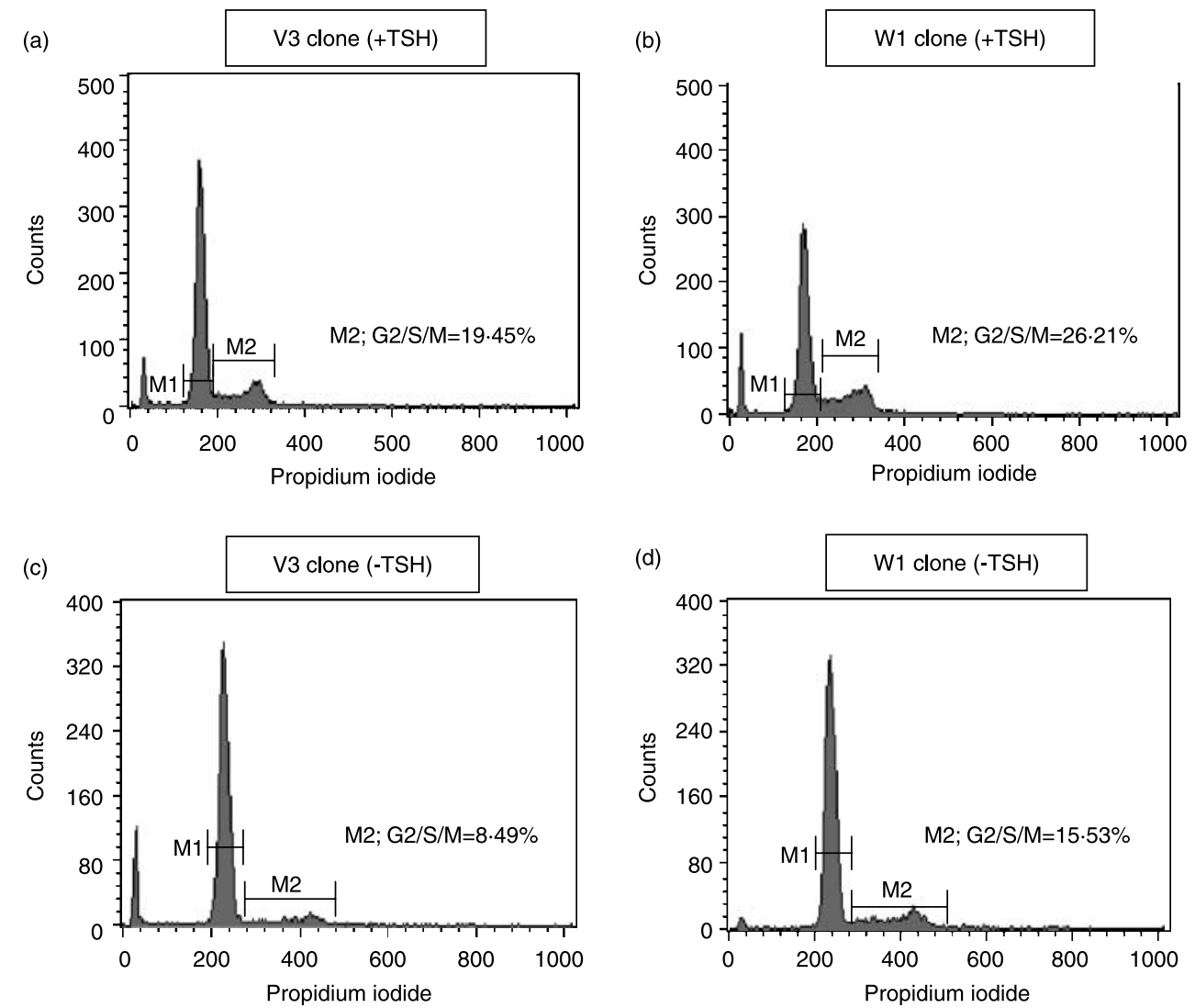

Figure 9 Cell cycle analysis in stable transfectant overexpressing Wnt-1. Cell cycle analysis of Wnt-1 overexpressing cells (W1) and vector-transfected cells (V3) was performed using flow cytometry. DNA content of cells stained with propidium iodide was measured and analyzed as described in Materials and Methods. Cell cycle distribution of V3 clone grown in the presence of TSH $(+\mathrm{TSH})(\mathrm{a})$, in the absence of TSH $(-\mathrm{TSH})$ for 6 days $(\mathrm{c}), \mathrm{W} 1$ clone grown in the presence of TSH $(+\mathrm{TSH})(\mathrm{b})$, in the absence of TSH $(-\mathrm{TSH})$ for 6 days $(\mathrm{d})$ are shown. Higher percentages of cells were in G2/S/M phase in W1 clone compared with V3 clone, both in the absence and presence of TSH. Representative results from each condition are shown. M1 indicates cells in G1 phase and M2 indicates cells in G2/S/M phase.

(V3; Fig. 11). In addition, these data suggest that activation of PKC and (serine phosphorylation) STAT3 is involved in the growth-stimulating effect exerted by Wnt-1 overexpression in FRTL-5 cells.

\section{Discussion}

Using a differentiated thyroid cell line, FRTL-5, we have examined the biological implications of activation of a Wntsignaling pathway. Moreover, we have shown that TSH can increase levels of Wnt-1, apparently and specifically; Wnt-1 overexpression enhances cell growth and relieves transcriptional suppression of the TPO gene. TPO is a critical enzyme for thyroid hormone synthesis in thyrocytes. We have suggested that the growth-promoting effect might involve activation of some components of a noncanonical Wntsignaling pathway, whereas relief of the transcriptional suppression of TPO was mainly through the activation of the Wnt/ $\beta$-catenin pathway, since Wnt-1's suppressive effect was duplicated by $\beta$-catenin overexpression.

In the FRTL-5 cell, TSH increased Wnt-1 protein and RNA levels, but not Wnt-5a or Wnt-3a. TSH also increased Wnt-1 levels should have increased the amount of $\beta$-catenin, because Wnt-1 classically activates the canonical Wntsignaling pathway, resulting in $\beta$-catenin accumulation (Cadigan \& Nusse 1997, Miller et al. 1999, Moon et al. 2004, Nelson \& Nusse 2004). However, surprisingly, exposure of FRTL-5 cell to TSH paradoxically decreased the amount of $\beta$-catenin. The cause of this phenomenon is not clear at this moment, although there are two possibilities that could be considered. First, stimulation of TSH signaling might increase the degradation of $\beta$-catenin in FRTL- 5 cells through an unknown mechanism. Secondly, Wnt-1 might not be the only functionally important Wnt protein in the FRTL-5 cell. This possibility still exists, although we did 


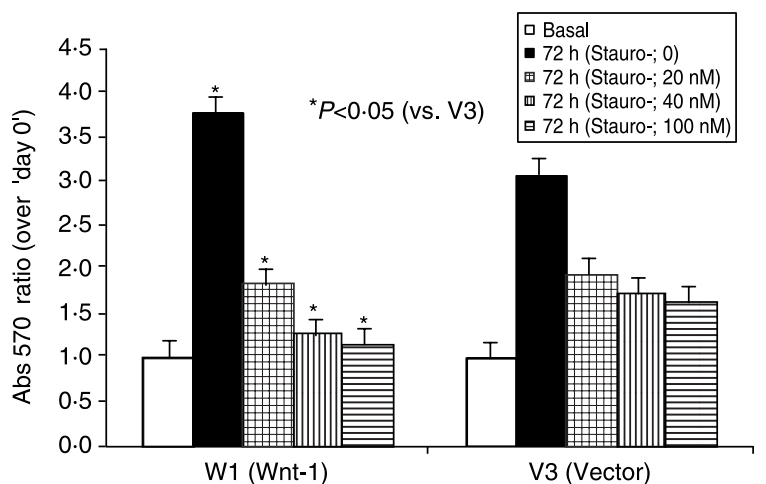

Figure 10 Wnt-1-induced increased growth rate of FRTL-5 cells is blunted in the presence of a PKC inhibitor, staurosporin. Growth rates of FRTL-5 cells stably transfected with Wnt- 1 expression vector (W1) or control vector (V3) were compared in the presence of staurosporin or control (DMSO) using MTT assay. Cells were grown in the presence of TSH. Staurosporin was added into culture media at $24 \mathrm{~h}$ after plating cells and MTT assays were done at $72 \mathrm{~h}$. Background absorbance (cell culture medium only) was subtracted to obtain actual absorbance. Absorbance values at $72 \mathrm{~h}$ are plotted relative to baseline absorbance (i.e. absorbance at day 0 ). Baseline value is the absorbance measured at $3 \mathrm{~h}$ after plating in each cell line. All values are mean \pm s.D. of $s$ independent wells. ${ }^{*}$ Indicates $P<0 \cdot 05$ when compared with V3 cells treated with the same concentration of staurosporin. Results presented are typical of two separate experiments.

exclude the presence of Wnt-3a and Wnt-5a. We did not, however, systematically evaluate the expression of all Wnt proteins in the FRTL-5 cell. Nonetheless, the fact that Wnt-1 protein is upregulated and $\beta$-catenin protein is simultaneously downregulated by TSH in FRTL- 5 cell appears to have very important biological implications based upon our results. TSH-induced increase in Wnt-1 appears to stimulate growth through activation of a PKC pathway and STAT3, whereas, the 'simultaneous' action of TSH to decrease $\beta$-catenin

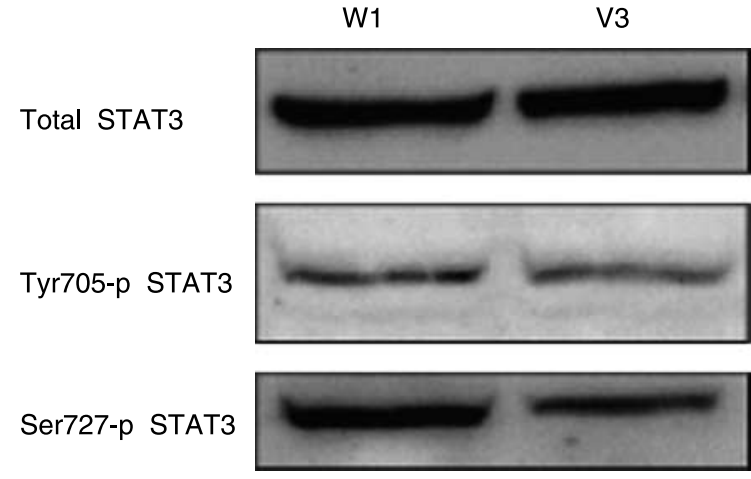

Figure 11 Wnt-1 overexpression increases STAT3 serine phosphorylation. Twenty micrograms cell lysates of Wnt-1-transfected (W1) or vector-transfected (V3) FRTL-5 cells grown in the presence of TSH ( $6 \mathrm{H}$ media) were subjected to SDS-PAGE and western blot analysis using antibodies against total STAT3, or STAT3 phosphorylated on serine 727 or STAT3 phosphorylated on Tyr 705. Results presented are typical of two separate experiments. protein relieves transcriptional suppression of a major functional protein, TPO. In this respect, it must be recognized that the thyrocyte is relatively unique in that TSH stimulates both growth and function of the cell. Thus, TSH may use the Wnt-signaling system as one means to 'simultaneously' increase both growth and function of the cell. This could be a new paradigm for explaining the physiological role of Wnt-signaling system in a differentiated mammalian cell.

Most target genes of the canonical Wnt pathway are positively regulated by $\beta$-catenin (Cavallo et al. 1997). The mechanism of transcriptional activation might be by the $\beta$-catenin/TCF/LEF complex acting directly as a transcriptional activator or by acting to displace a corepressor bound to TCF/LEF (Miller et al. 1999). Nevertheless, transcription of some genes, such as mouse osteocalcin (Cadigan et al. 2002) or shavenbaby, stripe, decapentaplegic, and daughterless genes of Drosophila (Payre et al. 1999, Piepenburg et al. 2000, Yang et al. 2000, Kahler \& Westendorf 2003) is suppressed by activation of the canonical Wnt pathway.

In this study, we found that the rat TPO gene is an example of a gene whose transcription is repressed by $\beta$-catenin. Thus, we showed that $\mathrm{ABC} / \mathrm{TCF}-1$ complex binds to oligonucleotide including consensus TCF/LEF-binding sequence on TPO-promoter, that this complex increases with $\beta$-catenin overexpression in FRTL- 5 cells, as measured by EMSA, but there is a 'simultaneous' major decrease in TPO RNA levels and lesser decrease in TSHR RNA. This is the first demonstration that $\beta$-catenin/TCF-1 complex acts as a transcriptional repressor by binding directly to the promoter of a target gene. In our study, $\beta$-catenin overexpression decreased the amount of mRNA for TPO more prominently than Wnt-1 overexpression, whereas the suppressive activity on TPO-promoter constructs was more remarkable with Wnt-1 overexpression. The cause of this discrepancy is not clear, but once again multiple possibilities exist. First, we examined the effects of Wnt-1 overexpression and those of $\beta$-catenin overexpression at the same time point after transfection. The expression vectors for Wnt-1 and $\beta$-catenin used in experiments might have different optimal times of expression, thereby causing the discrepancy between the results of northern blot analyses and those of the promoter studies. Secondly, because the efficiency of transfection is very low, it may be an issue of sensitivity in transient transfection experiments using FRTL-5 cells. In EMSA, the fact that NE from Wnt-1 overexpression did not increase complex formation between $\beta$-catenin/TCF-1 complex and oligonucleotide containing the TCF/LEF-binding sequence might also be due to the problem of transfection. Thirdly, Wnt-1 'simultaneous' overexpression of the $\mathrm{Ca}^{++} / \mathrm{PKC} / \mathrm{STAT} 3$ pathway, as in the case of stable transfectant of Wnt- 1 shown in this study, might add a confounding effect to a Wnt $/ \beta$ catenin pathway.

The fact that transcriptional repression of the TPO gene exerted by Wnt-1 overexpression was mainly through the activation of the canonical Wnt pathway (Wnt/ $\beta$-catenin) is further supported by the results of northern blot analysis of 
cells exposed to $\mathrm{LiCl}$. $\mathrm{LiCl}$ is a potent inhibitor of GSK-3 $\beta$ $(\mathrm{Ki}=2 \mathrm{mM})$, a key enzyme involved in degradation of $\beta$-catenin, as determined by in vitro assays (Klein \& Melton 1996). LiCl treatment $(2 \mathrm{mM})$ decreased the mRNA for TPO additionally with the overexpression of $\beta$-catenin or Wnt-1 regardless of the presence of TSH. This strongly suggests that $\beta$-catenin is primarily responsible for the transcriptional repression of TPO by Wnt activation of its canonical signaling pathway.

We evaluated the effects of activation of the Wnt-signaling pathway on the growth of FRTL-5 cell using a stable transfectant that overexpressed Wnt-1. In terms of activation of the Wnt/ $\beta$-catenin pathway, constitutive $\beta$-catenin activity has been considered as the main mechanism of growth stimulation (Miller et al. 1999, Polakis 2000, 2002). This is based on the fact that genes for c-myc and cyclin D1, which are known to promote cell proliferation, are direct targets of $\beta$-catenin (He et al. 1998, Shtutman et al. 1999, Tetsu \& McCormick 1999). However, the cellular $\beta$-catenin level of Wnt-1 overexpressing clone (W1) did not increase at all when compared with nontransfected FRTL-5 cells or to vectortransfected cells, arguing against the role of the canonical Wnt pathway in growth stimulation.

Further, as the increase in growth rate of $\mathrm{W} 1$ clone was abrogated by staurosporin, a PKC inhibitor, activation of the $\mathrm{Wnt} / \mathrm{Ca}^{++}$pathway is a potential candidate for the growth stimulation in Wnt-1-transfected cells. The mechanism of $\mathrm{Wnt} / \mathrm{Ca}^{++}$pathway activation leading to PKC activation is not well-documented currently, although there have been some reports that the Wnt signal at the cell membrane is recognized by specific subtypes of frizzled receptors (Sheldahl et al. 1999) and may function through activation of heterotrimeric G-proteins (Slusarski et al. 1997, Sheldahl et al. 1999). The phenomenon of a decrease in ABC protein both in the Wnt-1-transfected cells (W1) and in the vectortransfected cells (V3) cannot be explained at this time. Nonetheless, this still suggests that $\beta$-catenin does not have an important role in growth regulation of the FRTL- 5 cell.

We found that activation of the Wnt-signaling pathway is associated with STAT3 activation. STAT3 is of growing interest as an oncogene involved in cell-cycle progression, cellular transformation, and prevention of apoptosis (Bowman et al. 2000, Calo et al. 2003). Constitutively, activated STAT3 and STAT5 proteins are found in many types of human cancers and cancer cell lines. Genes for $\mathrm{Bcl}-\mathrm{x}_{\mathrm{L}}$, cyclin D1, p21 WAF1/CIP1, c-myc are known to be the targets of constitutively activated STATs (Bowman et al. 2000, Calo et al. 2003). In the case of STAT3, tyrosine 705 (Tyr 705) and serine 727 (Ser 727) are the important phosphorylation sites. We found that the amount of STAT3 protein phosphorylated on serine 727 was increased in the Wnt-1 overexpressing stable transfectant W1 clone, when compared with nontransfected FRTL-5 cells or to a vector-transfected clone. The increase in Ser727 phosphorylation of STAT3 seems not to be through the TSH/cAMP-signaling pathway, as TSH induces phosphorylation at both sites, Tyr 705 and Ser 727 in FRTL-5 cells (Park et al. 2000). As there is evidence for a role of PKC in serine phosphorylation of STAT3 (Jain et al. 1999), it is plausible that the Wnt-1 activation of the $\mathrm{Wnt} / \mathrm{Ca}^{++}$ pathway leading to PKC activation increased serine phosphorylation of STAT3 in the Wnt-1 overexpressing cell. Based on the fact that protein levels of ABC did not increase and serine phosphorylated STAT3 increased in the Wnt-1 overexpressing cells, we suggest that the activation of the noncanonical Wnt pathway, involving activation of PKC and serine phosphorylation of STAT3, is the main mechanism of the growth-enhancing effect observed in this cell.

In sum, by overexpressing Wnt- 1 and $\beta$-catenin in FRTL- 5 cells, we showed that activation of the Wnt-signaling pathway enhances cellular growth probably through a PKC pathway, which involves increased serine phosphorylation of STAT3. We also showed that activation of the Wnt/ $\beta$-catenin pathway can suppress transcription of the TPO gene by increased binding of $\beta$-catenin/TCF-1 complex to the TPO-promoter. TSH-induced decrease in $\beta$-catenin would relieve this suppression consistent with the well-known ability of TSH to increase TPO RNA levels in FRTL-5 cells.

\section{Acknowledgements}

The authors declare that there is no conflict of interest that would prejudice the impartiality of this scientific work.

\section{References}

Aza-Blanc P, Di Lauro R \& Santisteban P 1993 Identification of a cisregulatory element and a thyroid-specific nuclear factor mediating the hormonal regulation of rat thyroid peroxidase promoter activity. Molecular Endocrinology 7 1297-1306.

Behrens J, von Kries JP, Kuhl M, Bruhn L, Wedlich D, Grosschedl R \& Birchmeier W 1996 Functional interaction of beta-catenin with the transcription factor LEF-1. Nature 382 638-642.

Bidey SP, Lambert A \& Robertson WR 1988 Thyroid cell growth, differentiation and function in the FRTL-5 cell line: a survey. Journal of Endocrinological 119 365-376.

Bowman T, Garcia R, Turkson J \& Jove R 2000 STATs in oncogenesis. Oncogene 19 2474-2488.

Cadigan KM \& Nusse R 1997 Wnt signaling: a common theme in animal development. Genes and Development 11 3286-3305.

Cadigan KM, Jou AD \& Nusse R 2002 Wingless blocks bristle formation and morphogenetic furrow progression in the eye through repression of daughterless. Development 129 3393-3402.

Calo V, Migliavacca M, Bazan V, Macaluso M, Buscemi M, Gebbia N \& Russo A 2003 STAT proteins: from normal control of cellular events to tumorigenesis. Journal of Cellular Physiology 197 157-168.

Cavallo R, Rubenstein D \& Peifer M 1997 Armadillo and dTCF: a marriage made in the nucleus. Current Opinion in Genetics and Development 7 459-466.

Cerrato A, Fulciniti F, Avallone A, Benincasa G, Palombini L \& Grieco M 1998 Beta- and gamma-catenin expression in thyroid carcinomas. Journal of Pathology 185 267-272.

Clevers H 2000 Axin and hepatocellular carcinomas. Nature Genetics 24 206-208

Emami KH, Nguyen C, Ma H, Kim DH, Jeong KW, Eguchi M, Moon RT, Teo JL, Kim HY, Moon SH et al. 2004 A small molecule inhibitor of betacatenin/CREB-binding protein transcription. PNAS 101 12682-12687. 
Fabbro D, Di Loreto C, Beltrami CA, Belfiore A, Di Lauro R \& Damante G 1994 Expression of thyroid-specific transcription factors TTF-1 and PAX-8 in human thyroid neoplasms. Cancer Research 54 4744-4749.

Francis-Lang H, Price M, Polycarpou-Schwarz M \& Di Lauro R 1992 Celltype-specific expression of the rat thyroperoxidase promoter indicates common mechanisms for thyroid-specific gene expression. Molecular and Cellular Biology 12 576-588.

Garcia-Rostan G, Tallini G, Herrero A, D’Aquila TG, Carcangiu ML \& Rimm DL 1999 Frequent mutation and nuclear localization of beta-catenin in anaplastic thyroid carcinoma. Cancer Research 59 1811-1815.

Garcia-Rostan G, Camp RL, Herrero A, Carcangiu ML, Rimm DL \& Tallini G 2001 Beta-catenin dysregulation in thyroid neoplasms: down-regulation, aberrant nuclear expression, and CTNNB1 exon 3 mutations are markers for aggressive tumor phenotypes and poor prognosis. American Journal of Pathology 158 987-996.

Gumbiner BM 2000 Regulation of cadherin adhesive activity. Journal of Cell Biology 148 399-404.

He TC, Sparks AB, Rago C, Hermeking H, Zawel L, da Costa LT, Morin PJ, Vogelstein B \& Kinzler KW 1998 Identification of c-MYC as a target of the APC pathway. Science 281 1509-1512.

Helmbrecht K, Kispert A, von Wasielewski R \& Brabant G 2001 Identification of a Wnt/beta-catenin signaling pathway in human thyroid cells. Endocrinology 142 5261-5266.

Huang SH, Wu JC, Chang KJ, Liaw KY \& Wang SM 1999 Expression of the cadherin-catenin complex in well-differentiated human thyroid neoplastic tissue. Thyroid 9 1095-1103.

Isozaki O, Kohn LD, Kozak CA \& Kimura S 1989 Thyroid peroxidase: rat cDNA sequence, chromosomal localization in mouse, and regulation of gene expression by comparison to thyroglobulin in rat FRTL- 5 cells. Molecular Endocrinology 3 1681-1692.

Jain N, Zhang T, Kee WH, Li W \& Cao X 1999 Protein kinase C delta associates with and phosphorylates Stat3 in an interleukin-6-dependent manner. Journal of Biological Chemistry 274 24392-24400.

Jamora C \& Fuchs E 2002 Intercellular adhesion, signalling and the cytoskeleton. Nature Cell Biology 4 E101-E108.

Kahler RA \& Westendorf JJ 2003 Lymphoid enhancer factor-1 and betacatenin inhibit Runx2-dependent transcriptional activation of the osteocalcin promoter. Journal of Biological Chemistry 278 11937-11944.

Kaykas A, Yang-Snyder J, Heroux M, Shah KV, Bouvier M \& Moon RT 2004 Mutant frizzled 4 associated with vitreoretinopathy traps wild-type frizzled in the endoplasmic reticulum by oligomerization. Nature Cell Biology 6 $52-58$.

Kikkawa F, Gonzalez FJ \& Kimura S 1990 Characterization of a thyroidspecific enhancer located 5.5 kilobase pairs upstream of the human thyroid peroxidase gene. Molecular and Cellular Biology 10 6216-6224.

Klein PS \& Melton DA 1996 A molecular mechanism for the effect of lithium on development. PNAS 93 8455-8459.

Kohn LD, Saji M, Akamizu T, Ikuyama S, Isozaki O, Kohn AD, Santisteban P, Chan JY, Bellur S \& Rotella CM 1989 Receptors of the thyroid: the thyrotropin receptor is only the first violinist of a symphony orchestra. Advances in Experimental Medicine and Biology 261 151-209.

Kremenevskaja N, von Wasielewski R, Rao AS, Schofl C, Andersson T \& Brabant G 2005 Wnt-5a has tumor suppressor activity in thyroid carcinoma. Oncogene 24 2144-2154.

McMahon AP \& Moon RT 1989 Ectopic expression of the proto-oncogene int-1 in Xenopus embryos leads to duplication of the embryonic axis. Cell $\mathbf{5 8}$ 1075-1084.

Miller JR, Hocking AM, Brown JD \& Moon RT 1999 Mechanism and function of signal transduction by the Wnt/beta-catenin and $\mathrm{Wnt} / \mathrm{Ca}^{2+}$ pathways. Oncogene 18 7860-7872.

Mizuno K, Gonzalez FJ \& Kimura S 1991 Thyroid-specific enhancer-binding protein (T/EBP): cDNA cloning, functional characterization, and structural identity with thyroid transcription factor TTF-1. Molecular and Cellular Biology 11 4927-4933.

Moon RT, Kohn AD, De Ferrari GV \& Kaykas A 2004 WNT and beta-catenin signalling: diseases and therapies. Nature Reviews Genetics $\mathbf{5}$ 691-701.

Morin PJ 1999 Beta-catenin signaling and cancer. Bioessays 21 1021-1030.
Mosmann T 1983 Rapid colorimetric assay for cellular growth and survival: application to proliferation and cytotoxicity assays. Journal of Immunological Methods 65 55-63.

Nelson WJ \& Nusse R 2004 Convergence of Wnt, beta-catenin, and cadherin pathways. Science 303 1483-1487.

van Noort M, Meeldijk J, van der Zee R, Destree O \& Clevers H 2002 Wnt signaling controls the phosphorylation status of beta-catenin. Journal of Biological Chemistry 277 17901-17905.

Ortiz L, Aza-Blanc P, Zannini M, Cato AC \& Santisteban P 1999 The interaction between the forkhead thyroid transcription factor TTF-2 and the constitutive factor CTF/NF-1 is required for efficient hormonal regulation of the thyroperoxidase gene transcription. Journal of Biological Chemistry 274 15213-15221.

Park ES, Kim H, Suh JM, Park SJ, You SH, Chung HK, Lee KW, Kwon OY, Cho BY, Kim YK et al. 2000 Involvement of JAK/STAT (Janus

kinase/signal transducer and activator of transcription) in the thyrotropin signaling pathway. Molecular Endocrinology 14 662-670.

Payre F, Vincent A \& Carreno S 1999 ovo/svb integrates wingless and DER pathways to control epidermis differentiation. Nature 400 271-275.

Piepenburg O, Vorbruggen G \& Jackle H 2000 Drosophila segment borders result from unilateral repression of hedgehog activity by wingless signaling. Molecular Cell 6 203-209.

Polakis P 1997 The adenomatous polyposis coli (APC) tumor suppressor. Biochimica et Biophysica Acta 1332 F127-F147.

Polakis P 2000 Wnt signaling and cancer. Genes and Development $141837-$ 1851.

Polakis P 2002 Casein kinase 1: a Wnt'er of disconnect. Current Biology 12 R499-R501.

Saji M, Shong M, Napolitano G, Palmer LA, Taniguchi SI, Ohmori M, Ohta M, Suzuki K, Kirshner SL, Giuliani C et al. 1997 Regulation of major histocompatibility complex class I gene expression in thyroid cells, role of the cAMP response element-like sequence. Journal of Biological Chemistry 272 20096-20107.

Sheldahl LC, Park M, Malbon CC \& Moon RT 1999 Protein kinase C is differentially stimulated by Wnt and frizzled homologs in a G-proteindependent manner. Current Biology 9 695-698.

Shimura H, Okajima F, Ikuyama S, Shimura Y, Kimura S, Saji M \& Kohn LD 1994 Thyroid-specific expression and cyclic adenosine $3^{\prime}, 5^{\prime}$-monophosphate autoregulation of the thyrotropin receptor gene involves thyroid transcription factor-1. Molecular Endocrinology 8 1049-1069.

Shtutman M, Zhurinsky J, Simcha I, Albanese C, D’Amico M, Pestell R \& Ben-Ze'ev A 1999 The cyclin D1 gene is a target of the beta-catenin/LEF1 pathway. PNAS $965522-5527$.

Slusarski DC, Corces VG \& Moon RT 1997 Interaction of Wnt and a frizzled homologue triggers G-protein-linked phosphatidylinositol signalling. Nature 390 410-413.

Suzuki K, Lavaroni S, Mori A, Ohta M, Saito J, Pietrarelli M, Singer DS, Kimura S, Katoh R, Kawaoi A et al. 1998 Autoregulation of thyroid-specific gene transcription by thyroglobulin. PNAS 95 $8251-8256$

Suzuki K, Mori A, Ishii KJ, Saito J, Singer DS, Klinman DM, Krause PR \& Kohn LD 1999 Activation of target-tissue immune-recognition molecules by double-stranded polynucleotides. PNAS 96 2285-2290.

Tetsu O \& McCormick F 1999 Beta-catenin regulates expression of cyclin D1 in colon carcinoma cells. Nature 398 422-426.

Webster MT, Rozycka M, Sara E, Davis E, Smalley M, Young N, Dale TC \& Wooster R 2000 Sequence variants of the axin gene in breast, colon, and other cancers: an analysis of mutations that interfere with GSK3 binding. Genes, Chromosomes and Cancer 28 443-453.

van de Wetering M, Cavallo R, Dooijes D, van Beest M, van Es J, Loureiro J, Ypma A, Hursh D, Jones T, Bejsovec A et al. 1997 Armadillo coactivates transcription driven by the product of the Drosophila segment polarity gene dTCF. Cell 88 789-799.

Yang X, van Beest M, Clevers H, Jones T, Hursh DA \& Mortin MA 2000 Decapentaplegic is a direct target of dTcf repression in the Drosophila visceral mesoderm. Development 127 3695-3702. 
Yang-Snyder J, Miller JR, Brown JD, Lai CJ \& Moon RT 1996 A frizzled homolog functions in a vertebrate Wnt signaling pathway. Current Biology 6 1302-1306.

Yost C, Torres M, Miller JR, Huang E, Kimelman D \& Moon RT 1996 The axis-inducing activity, stability and subcellular distribution of $\beta$-catenin is regulated in Xenopus embryos by glycogen synthase kinase 3. Genes and Development 10 1443-1454.

Zannini M, Francis-Lang H, Plachov D \& Di Lauro R 1992 Pax-8,

a paired domain-containing protein, binds to a sequence overlapping the recognition site of a homeodomain and activates transcription from two thyroid-specific promoters. Molecular and Cellular Biology 12 4230-4241.

Received in final form 1 December 2006

Accepted 7 December 2006

Made available online as an Accepted Preprint 27 December 2006 